\title{
Best Practices to Address Inequities in Academic Support in the University Access Program
}

\author{
Lerato Sekonyela ${ }^{1}$ \\ University of the Free State, South Africa
}

\begin{abstract}
Even though access to higher education (HE) has increased drastically among many institutions globally, some challenges persist, among which are impediments to student success. These challenges could potentially hinder students' success and impede their smooth articulation to the preferred HE degree. Data were collected through focus group discussions that the FreeAttitude Interview technique facilitated. This study proposes potential strategies for implementing "best practices" to improve students' academic support in the University Access Program (UAP), particularly in the South African context. The proposed "best practices" are based on students who experienced challenges. Among these best practices are that students and tutors need to have regular meetings once or more per week, groups should not include more than fifteen first-year students, a student learning-centered approach should be employed, and students should be partners in the co-creation of the curricula and the co-evaluation of subjectrelated matters.
\end{abstract}

Keywords: academic support, best practices, inequities, University Access Program, South Africa.

Even though access to higher education (HE) has increased drastically among many institutions globally, some challenges persist. This paper proposes implementing "best practices" to improve students' academic support in University Access Programs (UAP) in South Africa. These challenges potentially could hinder students' success and further hinder their smooth transition to their preferred HE degree. Identified challenges students experience include unequal distribution of academic support. First, academic support inequities include a lack of tutoring and mentoring support, a lack of peer support programs, and inadequate IT support. Second is a lack of preparatory support programs because of the segregation of campuses, invisibility of learning centers, and inadequate and/or limited academic advising (Sekonyela, 2021). The focus of this paper is best practices to address inequities in academic support.

This paper reflects on experienced challenges that registered University Access Program (UAP) students articulated in a university in South Africa. This paper suggests the adaptation, introduction and implementation of best practices in the South African context based on student' challenges. Amid ongoing discussions to decolonize education, South African Higher Education Institutions (SAHEI) need to re-focus and re-evaluate their systems. They need to identify the best practices best suited for students and adapting and paying attention to cultural relativism while maintaining competitive academic global citizens.

Students in SAHEI continue to face the challenge of accessing higher education institutions due to school performance. Therefore, to address this issue, some SAHEIs have developed different strategies and initiatives, such as widening participation, university access programs, foundation programs, and supplemental instruction. The University of the Free State

\footnotetext{
${ }^{1}$ Corresponding Author E-Mail: mputsoel@ufs.ac.za
} 
(UFS) in South Africa introduced UAP in 1993 to assist many deserving students who did not meet university admission requirements due to underperformance at the school level (Marais \& Hanekom, 2014). UAP seemed to address the issue of access to higher education institutions. However, since its inception, not much has changed in addressing problems or how the program functions. Education evolves, and every year, there is a different cohort. Student needs differ from cohort to cohort; therefore, a need exists to introduce and implement best practices to improve academic support to address inequities, particularly among institutions with "multicampuses." Institutions globally have many best practices that they implement in addressing students' needs; this paper addressed a few that speak to the challenges in UAP.

\section{Best Practices for UAPs}

Sekonyela (2021) identified the challenges that UAP students experienced, consequently leading to the proposal of best practices with the potential for addressing and minimizing those challenges. These included addressing inequities in academic support such as tutoring and mentoring programs (supplemental support service, South African mentoring experience), peer support programs (student-led, individual-created courses, peer network program), and IT access resources (university-based virtual learning environment, blended learning and information, and communication technology). This paper discusses these issues.

\section{Supplemental Support Service}

Jones and Lau (2008) noted the need for tutorials in UAPs, and Arendale (2010) highlighted Supplementary Instruction (SI) as one of the most useful practices. In this paper, SI is referred to as Supplemental Support Service (SSS), as SI seems to be instructional, thereby taking away student agency. The intention with SSS is to increase student academic performance as the program targets difficult academic courses. Hall and Collins (n.d) revealed that the UK government recognized that all students deserve excellent teaching, regardless of their background. The American government introduced a teaching excellence framework consisting of peer-assisted learning (PAL) whereby senior students act as tutors to first-year students. Considering all of the above, tutoring support is lacking in the UAP. As stated earlier, the SSS identifies difficult courses; however, determining difficult academic courses can be challenging, as it poses complexities in measuring student success interventions. Because universities have new cohorts of students each year, the groups from different years cannot be treated the same. For example, current students may be academically stronger in a particular subject or module than students of the previous year, or vice versa.

Hall and Collins (n.d.) point out that PAL is grounded in SI. Hall and Collins concurred with Jones and Lau (2008) and Arendale (2010) on PAL's purpose by highlighting that SI targets at-risk courses rather than providing remedial interventions to at-risk students. In contrast, Hakizimana and Jürgens (2013) regarded SI and the peer teaching/learning experience program (PTLEP) as similar to PAL but also different as the group sizes differ. Usually, an SI group consists of 100-300 students in one venue, whereas a PAL group consists of 10-20 students. Therefore, PTLEP in this regard will be discussed as a possible strategy. In contrast to this, Hilsdon (2014) placed SI in developmental education as it focuses on issues of achievement-related underprepared students in HE and therefore views SI as an effective and essential learning strategy. 


\section{South African Mentoring Experience (SAME)}

Harwood et al. (2015) stated that the Australian Indigenous Mentoring Experience (AIME) program has a well-established curriculum. In this paper, AIME is referred to as the South African Mentoring Experience (SAME). Drawing from Harwood et al.'s (2015) work and placing it in the South African context, SAME presenters can deliver curriculum to groups of students and their university mentors. In this case, the SAME presenters and knowledgeable academic staff members responsible for transferring expertise to UAP students need to be trained. Additionally, SAME presenters can be assigned mentors, mentors to offer support to presenters; in-turn, presenters can become students' mentors. Once students and their mentors have established a trusting relationship, the mentors consequently serve as tutors. During program delivery, a mentor supports and encourages a mentee through different academic tasks. Mentors also act as role models to the mentees (Harwood et al., 2015). Can SAHEIs adapt this strategy and make it user-friendly for their students?

Waller et al. (2017) mentioned a tutoring and mentoring outreach project at a university in the United Kingdom where they combine tutoring and mentoring. Tutoring by knowledgeable undergraduates provides other undergraduate students with a valuable resource that would otherwise be less accessible. New students to HE can benefit significantly from being mentored by confident and capable undergraduate students, with first-hand knowledge about what a university was actually like, otherwise called a form of "cultural capital." Such a practice offers a role model to whom the students can relate and reassures them that the university can be open to all (Harwood et al., 2015).

Waller et al. (2017) further highlighted that "the main focus is on reinforcing and extending subject knowledge" (p. 6). Additional focuses include remedial work, revision guidance, and examination techniques. In mentoring, delivery is through an informal conversation where mentees are probed for information and insights into students' actual university experiences. Unfortunately, tutoring programs are seemingly rare in South African universities that offer UAP, and if tutoring programs are implemented, they are mostly on mainstream campuses but seldom on UAP campuses.

Waller et al. (2017) noted that, in terms of student academic understanding, “...students achieved better grades in formative assessments after taking part in the scheme as they were more confident with theories" (p. 6). Additionally, they stated that lecturers reported an "increased engagement with the subject, leading to more enjoyment of the lessons and better subject knowledge" (p .6). Furthermore, Waller et al. (2017) and Harwood et al. (2015) maintain that there was increased enthusiasm for the subject matter. Lecturers reported that the support offered in one-on-one or small group settings was particularly beneficial. Another benefit is the improved writing skills of students for whom English is an additional language, which is also an issue of growing concern. Therefore, SAHEIs need to firmly practice a studentcentered approach in which students as co-creators of curricula.

\section{Student-Led, Individually-Created Course (SLICC)}

Speirs et al. (2017) suggested that students be partners in the co-creation of curricula and co-evaluating or co-grading of subject-related matters. They termed this partnership Student-Led, Individually-Created Course (SLICC), which can be implemented as a strategy to address the need for peer support programs to improve academic support in the UAP. Students can be awarded space in co-creating the curricula by involving them in developing academic activities and assessments. This can potentially increase student motivation and engagement in subject matters. In their study, Speirs et al. (2017) highlighted the positive outcomes, including 
increased engagement and student motivation. It seems as if SLICC provides benefits similar to those of the tutor and mentor scheme that Waller et al. (2017) highlighted.

It seems as if UAP students are informed of what needs to be done in their academic endeavours without them giving any input. O'Shea et al. (2016) conducted a study at a university in Australia and shared the same sentiment: in most HEIs, the student's voice is absent and silent. Speirs et al. (2017) suggested that one way to foster student engagement is through an emphasis on "the ways in which individuals interact and develop" (p. 52) by including students in curriculum development, thereby allowing students' agency. Student agency can be maintained by involving them in developing content or module-specific activities to facilitate academic growth.

Wanner and Palmer (2015) suggested "encouraging students to engage with the curriculum expectations can assist them in becoming independent learners" (p. 357). Wanner and Palmer (2015) highlighted the significance of students and lecturers as partners in learning and assessment. When awarding students such an opportunity to provide input in assessment processes, the effects will lead to student engagement and motivation. Therefore, when students are awarded space for engaging with a lecturer or instructor, it becomes easy for student) to indicate where they struggle and seek clarity. Segabutla and Evans (2019) suggested that when students could communicate their struggles with a lecturer, the lecturer can establish different modes to clarify course content. This can be through the "use both verbal and non-verbal messages" (p. 116), facilitating and stimulating the learning process. Similarly, a lecturer can "organise information so that it is comprehensible to students by repeating and rephrasing ideas, using examples and practical applications, or by emphasising main points" (Segabutla \& Evans, 2019, p. 116). Similarly, in Egan's (2015) study, it emerged that when students develop, design, and co-create curricula, students can develop their "own learning goals and to strategically create their own course of study in line with those goals" (p. 77). Therefore, due to student involvement in curricula development, they are more likely to benefit from such development (Egan, 2015). In addition, Darling (2015) seems to hold the same sentiments: when students are involved in curriculum development and design, they learn to become members of the higher education community, thereby creating peer networks.

\section{Peer Network Program}

Kaldi and Griffiths (2013) stated that there must be institutional influences for students to succeed in their academic careers like support by peers and non-institutional like support by family and friends. Individual factors such as personal motivation and confidence, and collaborative factors, such as peer networks, are vital for student success. This notion of using different modes of learning can facilitate and stimulate the student learning process (Segabutla \& Evans, 2019).

Kaldi and Griffiths (2013) reported that even a small amount of institutional support was significant in student retention with the potential to progress and transition to the next or higher level of study. Therefore, the establishment of a peer network seems essential. Hakizimana and Jürgens (2013) viewed a peer network as a strategy involving interaction between peers of the same educational level and interactions with peers from different educational levels. Through a peer network, peers become a source of information for each other. Therefore, learning can be seen as involving reciprocal elements. In other words, students are involved collaboratively in the learning process. Hakizimana and Jürgens (2013) also suggest that in a peer network, peers share abilities, have discussions, and challenge their partial and incomplete knowledge.

Hakizimana and Jürgens (2013) suggested that students develop networks to communicate knowledge and news between themselves and sometimes to collaborate in lesson planning or other assignments. In a study that Kaldi and Griffiths (2013) conducted in Greece, 
students developed networks to exchange news and knowledge about the course. Similarly, in the United Kingdom, students also drew on peer information exchange from other students to help with lesson planning and course assignments (Kaldi \& Griffiths, 2013). This strategy can be beneficial for UAP students. In the same sense, peers develop and assist each other in using technology, particularly for those lacking such skills.

\section{Participatory Action Research}

Participatory action research (PAR) was chosen as the research methodology in this study because one of its purposes is to improve the quality of people's organisations and lives. Therefore, employing PAR afford space to identify 'best practices' for UAPs. Furthermore, researchers who employ PAR, study issues that relate to social problems, and that constrain and repress the lives of students and educators (Creswell, 2012, p. 582). Additionally, Marincowitz (2003, p. 595) indicates that PAR is a research process that focuses on improving quality of service by means of a self-reflective process, exploring and problem solving. Similarly, Ary et al. (2010, p. 515) articulate that PAR is emancipatory and transformational, and aims to challenge unproductive ways of working. Consequently, employing PAR in this case has the potential to raise awareness of students' challenges, informing stakeholders of the need to emancipate and transform UAPs. This will translate to improvement of services across campuses.

\section{Data Collection}

Data was collected through focus group discussions facilitated by the Free-Attitude Interview (FAI) technique (Mahlomaholo, 2009; Nkonyane, 2014). During discussions, one theme amongst others stood out, which suggested that students felt the need for academic support to improve. Co-researchers believe that improvement in academic support will facilitate and propel them to realise their capabilities. FAI helps discover information that one would not otherwise access, that is, it becomes easier for students to voice their concerns when they realise that others have similar experiences. Therefore, the co-researcher were more comfortable to speak out and engage in discussions; they also provided evidence to reaching conclusions from post hoc analysis of separate statements from each discussion. The co-researchers were sourced from UAP in South Africa. During sessions (focus group discussions), the researcher took steps to ensure minimal interruptions. The telephone was disengaged and a 'Do not disturb' sign was placed on the door to keep uninvited guests from entering.

The co-researchers were sourced from a UAP in South Africa. During focus group discussion sessions, the researcher took steps to ensure minimal interruptions. The telephone was disengaged, and a "Do not disturb" sign was placed on the door to keep uninvited guests from entering. Sessions were on UAP campus. We had three (3) sessions per week, depending on the need; other weeks, more sessions were held. The data were collected from 28 February 2018 to 3 December 2018.

\section{Data Analysis Method}

Data was analysed by means of Critical Discourse Analysis (CDA). Focus group discussions worked well with CDA, in this study. As central to CDA was the understanding that discourse was an integral aspect of power and control. This method was chosen because it allows the researcher and the co-researchers to take control of discussion, and no one feels forced to say something that they were uncomfortable sharing with the group (Babbie \& 
Mouton, 2005; Lazar 2005). FAI and CDA enabled knowledge creation and informed critical aspects pertaining to the study (Lazar, 2005; Weninger, 2012).

\section{Participants}

The participants, who were UAP students, were co-researchers. They were purposefully chosen based on the following characteristics (Pascoe, 2014; Strydom et al., 2004; Wildemuth, 2009): They were UAP students registered in the Faculty of Humanities, with sociology as one of the major modules at a major multi-campus public university in South Africa. Gatekeeping and ethical clearance were obtained from the university. Pseudonyms were used to protect coresearchers, who all voluntarily participated. They were informed of the goals of the research and the processes and procedures. Co-researchers were provided with the consent form, and were allowed to take it home. It was administered in this manner so that they did not feel coerced into participating, and afforded them space to make an informed decision. Those interested in participating returned signed consent forms. The researcher and co-researchers worked in 3-5 groups of 10, as small groups allow for better engagement and enhance understanding.

Participants were referred to as co-researchers as they collaborated in exploring and identifying problems and possible best practices. All co-researchers were involved through the process. This process allowed minimal power dynamics, which could hinder participation.

\section{Functionalism as a Framework}

Functionalist proponents believe that social reality is largely what people perceive it to be; it exists as people experience it and assign meaning. Social reality is fluid and fragile, and people construct it as they interact with others in ongoing communication and negotiation processes. Furthermore, functionalists also believe that social life arises in people's subjective experiences as they interact with others and construct meaning. Therefore, as registered UAP students, the participants were in the best position to provide insightful information of their experiences and challenges, consequently giving light to developing strategies.

Functionalism allowed for a better understanding of the challenges that UAP students experienced and facilitated collaboration among the co-researchers in developing the strategy. Moreover, the argument laid by functionalism is that society consists of social institutions, and for society to function smoothly and survive, all the parts that exist within a social institution need to function interdependently and adapt to the ever-changing education environment (Benokraitis, 2016; Ferrante, 2013, 2016).

Functionalism uses a structural explanation to emphasize how interdependent parts fit into and operate to sustain an overall system with specific parts serving complementary and specialized supporting roles for the whole (Neuman, 2014). Functionalism was chosen because it is concerned with student experiences. Therefore, employing functionalism, a researcher can understand students' experiences and challenges and discover how students construct meaning in their setting. The purpose was to determine what actions mean to those who engage in them, to understand how subjectively they experience the challenges.

Merton (1937) asserted that from a functionalism standpoint, knowledge creation depends on social position. For Merton, the nature of knowledge and the reality of such knowledge that humans hold are primarily based on individual standing in society (Chojnacki, 2015; Merton, 1937). For Merton, there is no one reality or nature of knowledge. Rather a person's standing in society gives way to the reality that he or she holds and the knowledge based on experiences. Moreover, every society has institutions, including education, and such institutions perform functions. According to Merton (in Benokraitis, 2016; Ferrante, 2013, 2016) functions can be manifest or latent. In other words, functions can be intended or unintended with expected or unintended consequences. Therefore, the focus is on manifest and 
latent functions performed by education (particularly higher education institutions). Institutions perform expected functions; however, institutions could also find themselves amid dysfunctions. Merton (in Benokraitis, 2016; Ferrante, 2013, 2016) explains dysfunctions as human actions that cause harm to the system and actions that expose unintended consequences (e.g., limited access to academic support that hinders academic success) (in Benokraitis, 2016; Ferrante, 2013, 2016).

Also, Merton (in Benokraitis, 2016; Ferrante, 2013, 2016) highlights that human actions can also hurt a system, and these actions are called latent dysfunctions. In this particular case, the consequences are usually unintended. Even though higher education institutions mean well by introducing the UAPs, the institutions seem to contribute to dysfunctions. These dysfunctions come in many forms, such as inequities in academic support and preparatory support programs (Arendale, 2010; Hlalele, 2010).

\section{Findings}

During the course of this study, UAP challenges were identified, which facilitated suggested practices to improve academic support for students. Therefore, due to collaborative nature of this study, co-researchers suggested the kind of support needed to enable adaptation to HEI, and which will facilitate progression. Therefore, findings are presented below. In addition, to protect and maintain anonymity and confidentiality of co-researchers, pseudonyms are used. Additionally, the following ethics were taken into consideration, voluntary participation, and informed consent to voice record.

Ary et al. (2010) in PAR, triangulation is significant, as researcher use of multiple sources of data that enhances collaboration and avoid relying on a single source for data hence the adoption of the strategy. Similarly, functionalism highlights that parts within an institution need to work together (interdependently) for the institution to thrive and to continue to exist (Ferrante, 2016). Hence, in this study, the researcher and co-researchers collaboratively developed a strategy to improve the academic support of UAP students.

\section{Supplemental Support Services (SSS)}

The intention with SSS is to increase student academic performance. The programme is said to target difficult academic courses and modules. Students deserve excellent teaching despite their background (Hall \& Collins, n.d), therefore the UK government introduced a teaching excellence framework called peer assisted learning (PAL). PAL is facilitated by senior students acting as tutors for first-year students. This research study identified lack of tutoring support in the UAP, Sociology was treated as one of the difficult modules. The researcher and co-researchers worked in groups of 10, as small groups allow for better engagement and enhance understanding.

Lydia: Since we started working in this group, I now enjoy Sociology. I am able to ask questions without fear that other students will laugh at my English, and I do not fear irritating my facilitator.

Sizwe: You have no idea how comfortable I feel in this group, and another thing I like is like we have come to work together in this group, we now help each other.

Zizi: I am so grateful that I decided to be part of this group because we get to be challenged and in that way, we can see where we are lacking. 
Also, having someone to rely on when I don't understand, having someone to show me how to take notes and how to study helps.

From co-researchers response above, it seems that they have benefited greatly from SSS, namely having access to a tutor. However, in this research study, SSS was facilitated in a collaborative manner, everyone as a co-researcher played a vital role. In the UK, SSS is facilitated by senior students and not by academic staff members (Hall \& Collins, n.d.). From the above experiences that the co-researchers were willing to share, it seems evident that when students are awarded an opportunity and comfortable space to engage with the academic related material, their understanding, engagement and motivation with that particular module improves quite a lot (Hakizimana \& Jürgens, 2013; Hilsdon, 2014).

\title{
South African Mentoring Experience (SAME)
}

Mentoring appear to be one of the programmes beneficial to first-year students. The mentoring experience seems to offer benefits similar to those of SSS (Harwood, et al., 2015). During program delivery, stakeholders collaboratively, with the intention to support and encourage each other through different academic tasks. However, roles might shift at some point, for example, the researcher can act as a mentor to offer support and encouragement, particular with difficult subject matters. Moreover, co-researchers collaboratively work together in achieving the desired goal (Harwood et al., 2015). For the co-researchers, this programme offered support, as is evident from the responses below:

\begin{abstract}
Mamello: ... so having this group and you helps. At times, because we are told that we are rejects, we wanted to give up on our studies. ... Like when we started this group, and someone suggested that we formulate a goal that we want to achieve, that no one in this group should feel little. That gave me hope that at least when I want to cry, or need help, I have someone to talk to.
\end{abstract}

Lydia: What I like about this group is that we work together...

Zizi: You see now..., we know who is good at what module, so even after our discussions in this group we still help each other.

Kate: We do work together as a group in different modules, when we work together, the other students explain in our language (referring to mother tongue) in that way things are easier to understand.

In one study conducted in England, an outreach project combining elements of tutoring and mentoring was discovered (Waller et al., 2017). Therefore, this research study adopted similar elements that is, combination of mentoring and tutoring. The researcher and coresearchers played both roles in that learning was collaborative. A similar outreach project was appreciated by the co-researchers when sharing experiences. They indicated that working in isolation at university is not an option, especially if a student is working towards a specific goal. They further stated that tutoring and mentoring by knowledgeable individuals are beneficial, and that it reinforces and increases subject knowledge. Therefore, through informal conversation the co-researchers were able to engage in subject matters other than that intended for this study (Harwood et al., 2015). This enabled them to identify whom to engage with in terms of their other modules. Furthermore, the co-researchers appreciated the benefits of this group with the following remarks: 
Zizi: ...like what you did to us was useful, it was useful, it was useful a lot. Because, if we like look our results right now, it shows that there is change somewhere somehow. Like, already now, I think we going to promote the module, unlike first semester it was challenging, and I think someone did not pass the module. So... since you came into our lives in our study like helping us with Sociology, you helped us a lot.

Edward: ...unlike first semester, because this semester we had someone working with us, I passed. First semester was hard, I didn't understand, and I was scared to tell my facilitator that I was lost in class.

\section{Student-Led, Individually-Created Courses}

Another strategy that can be used to address the need for peer support programmes in an effort to improve academic support in the UAP, is student-led individually-created courses (SLICC). For Speirs et al. (2017), the implementation of SLICC involves students as partners in the co-creation of curricula and the co-evaluation of subject related matters. To increase student motivation and engagement, is by awarding students space in co-creating the curricula, and by involving them in the development of academic activities and assessments (O'Shea et al., 2016). In this case, the co-researchers shared their experiences in terms of learning:

Lydia: ...I do formulate own questions, it helps...

Boitumelo: ... it helps when you have someone who challenges you to see whether you understand... we come up with different questions, and try to answer them...

Mamello: We also ask ... to check if we have approached the questions right...

From the above shared experiences, it is evident that the co-researchers created their own curricula by formulating questions, and collectively worked on answering such questions. In a study by Egan (2015), benefits emerged when students are engaged in the development of curricula. Students benefit in that they are in a position to develop learning goals and are able to create a course of study aligned with those goals (Egan, 2015). The co-researchers also indicated that formulating their own questions helped with the understanding of course content, and when they understood the course content, it became easier to engage with the subject and with fellow students. Additionally, from co-researchers shared experiences, it seems that they benefited from creating their own questions in preparation for tests or exams as they aligned their goals with those of the module.

In some HEIs, students seem to lack agency because they are silenced. Students are not involved in academic related matters, but only informed. Lack of student agency was also evident at a university in Australia (O'Shea et al., 2016). Therefore, SLICC can be implemented to address the issue of lack of student agency (O'Shea et al., 2016; Speirs et al., 2017). Student agency seems to be lacking in UAPs as well, as is evident from the following response:

Mamello: ...we are scared to ask our facilitators to see whether we understand and... are on the right track. 
Even though the co-researchers seemed to experience challenges in engaging with their facilitators during lectures, it seems as if they, as a collective engaged in the subject matters after class, and that ameliorate motivation. According to Wanner and Palmer (2015) and Darling (2015), the implementation of SLICC aid students in becoming independent, and increases student engagement and motivation. Consequently, students learn to become members of the HE community by being involved in curriculum expectations. That is, the coresearchers as a collective in this research study, collaborated in working on different modules outcomes.

\section{Peer Network Programme}

For Hakizimana and Jürgens (2013), the availability of a peer network programme affords students a space to communicate knowledge and news among themselves, and to collaborate in planning and completing assignments. Additionally, in Kaldi and Griffiths' (2013) study it is revealed that through the availability of peer network spaces, students in Greece exchanged news and knowledge about the course. Similarly, in England, students exchanged information with each other and helped each other with lesson planning and assignments (Kaldi \& Griffiths, 2013). This seems to have a positive impact on student learning, progression and retention. Similarly, in this study, the co-researchers had a space to collaborate as peers, and below are the responses relating to peer network:

Zizi: ...since you started this group, as a group if we work together we
can make it, and pass with flying colours.....

Kate: We do work together as a group in different modules, when we work together, the other students explain in our language (referring to mother tongue), in that way things are easier to understand.

From the above, it seems as if the co-researchers worked together to achieve the desired goals. They also indicated that they learned and understood better when they shared and discussed information among each other.

Peer network in this research study was facilitated by the researcher, unlike the study by Kaldi and Griffiths (2013) where the peer network was facilitated by second- and third-year students. However, the researcher as part of the team engaged with the co-researchers in lesson planning and assignments. Gale and Parker (2014) posit that institutions that initiate peer network schemes, by providing role models and other peer support systems, do so with the intention of benefiting students to successfully progress through HE. This seems to agree with the functionalist view that there are greater benefits when functioning as a collective, including providing students a sense of collegiality (Ferrante, 2016; Radulović \& Krstić, 2017; Stewart \& Zaaiman, 2015).

\section{Discussion}

HE students particularly UAP encounter a number of challenges before and after enrolment. Therefore, Sekonyela (2021) identified some of the challenges UAP students experienced, consequently leading to identified best practices to improve academic support, and the implementation thereof. Wilson-Strydom (2015) suggests that participation in South African universities has improved, and students have to be retained. Therefore, the kind of support students are awarded plays significant role in completing a HE qualification. This confirms that institutions need to be aware of and understand the challenges students are facing, for instance, in this case the nature of the academic support available, if any (Diaz et. al., 2021). 
CDA was chosen for the following reasons, 1) it aims to question and criticise discourses; 2) reveals the contradictions within and between discourses, the limits of what can be said and done, and the means by which discourse makes particular statements seem rational and beyond all doubts, even though they are only valid at a certain time and place. 3) Selection and preparation of data for specific analyses is purposeful. In this research study, data was selected and downsized according to relevant criteria that is themes were identified and grouped. 4) transcription of tape-recorded data was employed. 5) Formulation of critique, meaning the interpretation of results should be dealt with taking into account the relevant context knowledge (Wodak \& Meyer, 2009). Therefore, the following were found essential for the effectiveness of the proposed best practices. That is, these components seem to be equivalent to the discussed best practices in relation to UAP.

\section{Sustenance of Academic Support}

Regular meetings. To sustain academic support in the UAP, students and tutors need to have regular meetings once or more per week, depending on students' needs (Waller et al., 2017) therefore, in this study, similar approach was followed as students came to researcher with different kinds of needs. In addition, tutors work with small groups in sessions that last from 30 minutes to two hours as suggested by Hakizimana and Jürgens (2013, p.106), working in small group benefitted students, in that everyone had the opportune to seek clarity on subject matters without fear. During the course of this study, sessions were mostly conducted in preparation for tests and exams and other forms of assessment such as assignment writing. Working in small groups seemed beneficial in that every student had an opportunity to ask questions, as questioning is an important aspect in education in order for a student to attain better understanding and clarity in subject matters (Rossouw, 2020, p. 77). In these sessions, students were awarded space to work collaboratively and with peer support (SSS leaders) who are academically successful and performed well in that specific course. This assertion supports functionalist proponents in that when parts co-exist and work interdependently, society functions smoothly and thrives (Reed et al., 2015; Waller et al., 2017).

In this research study, the components of SSS sessions included weekly meetings between the researcher and the co-researchers. It was collaboratively agreed to have the meetings at the end of the week. This was to allow the co-researchers (students) enough time to work on their notes, obtain clarity from facilitators, and then identify challenging sections of the module. The researcher as a mentor and a tutor was then in a position to reinforce and extend subject knowledge (Waller et al., 2017). Reed et al. (2015) suggest that mentoring and tutoring programmes should successfully impact on students in that students' confidence should improve, motivation levels increase and an increase in capacity be evident. From the responses below it is clear that the co-researchers seem to support Reed et al. suggestion, and appreciated the kind of support they received in preparation for tests, assignment and presentations: Sizwe said "...like now, I can tell the upcoming students to ask for help, if they find Sociology difficult, even with any other module... You must start talking to people so that you can help each other and find help. ..." Zizi said, "...I think you should also call us to come and help other students". The latter response seems to also be willing to assist in coming students, due to appreciation of access to support. As Reed et al. (2015) suggested that mentoring should improve students' confidence, this is evident in this statement "...I think you should also call us to come and help other students".

As suggested by Hakizimana and Jürgens (2013), one of the components of SSS is to have regular meetings or sessions where students work collaboratively and with peer support of SSS leaders who have been academically successful or performed well in that course. This assertion also seems evident in co-researchers perspective as they seemed to appreciate the 
collaborative space where they worked together to discuss, compare notes, and work in groups to prepare for test and other forms of assessment.

The purpose of regular meetings between the co-researchers was to ensure that they were prepared for assessments. This entailed the co-researchers identifying difficult course sections, where after open discussions on the specific matters were held. This was conducted in a collaborative manner and to offer support to every co-researcher (Hilsdon, 2014). One of the defining results was that co-researchers' confidence improved because the supportive space allowed them to freely ask for more clarity if they did not understand a specific aspect.

The researcher took the role of mentor and tutor, the researcher was available to support students with their academics, and where deemed necessary, more specialized support was provided (Gale \& Parker, 2014; McFarlane, 2016). Tutoring was evident in that co-researchers shared strategies that would enhance academic success. While mentoring ensured in specialized support in the form of one-on-one sessions (researcher - co-researcher) (Rawlinson \& Willimott, 2016; Waller et al., 2017). It was important to have one-one-one sessions also as the researcher observed that during group sessions, some co-researchers were too shy to say that they were still experiencing challenges with the module.

Student-tutor ratio. Rawlinson and Willimott (2016) suggested that each mentor as a tutor should have a manageable group of not more than fifteen first-year students. Furthermore, mentors as tutors need to remain in contact with their groups for the duration of their first year of study. This was the case in this study, that is researcher and co-researchers were in constant contact, and it was done to enable UAP students to smoothly navigate HE. A mentor must have the following qualities for the process to be successful: "effective communication skills, leadership, empathy, and commitment to own studies" (p. 44). Additionally, Peck et al. (2010) suggest a reciprocal relationship between students and tutors. The co-researchers responded as follows with regard to group work:

\begin{abstract}
Mamello: ...during these sessions we learned that working with my group members does help. I was comfortable in that small ideas means something when someone would not understand, you made us realize that what we thought a small idea, was actually a good and big idea, which made us have good assignments and presentations.
\end{abstract}

Lydia: ... in here, I am comfortable in that in here even when I am wrong, I am corrected in a nice way, and that made me accept my mistakes, and I was comfortable to say when I don't understand. I was also comfortable in that even if I was wrong, at least my idea was heard, and even the group has always been willing to help, which is not the case in class with facilitators.

From above statements, co-researchers seem to support Peck et al. (2010) in terms of the qualities that a mentor/tutor need to have. One of the characteristics is effective communication. Co-researchers' use of statements and words such as "you made us realize that what we thought a small idea, was actually a good and big idea". Additionally, co-researchers seemed to be committed to their studies, this is indicative in this statement "...even the group has always been willing to help...".

In addition, for mentoring and tutoring programmes to be successful, the programmes must have low student-tutor ratio, increase capacity, increase confidence and sense of belonging, as well as increase motivation. Complementary areas should include raised selfawareness, informed decision-making and enhanced study experience (Reed et al., 2015). From the co-researchers point of view, working in small groups or having a low student-tutor ratio really made a positive impact on them as they have learned that working in a group is helpful. 
Seemingly, they implied that they have benefited in the following ways, namely an increased understanding of the module, enhanced engagement with the module and an increase in motivation.

Additionally, a reciprocal relationship between co-researchers, as Peck et al. (2010) suggest, was evident as the co-researchers articulated that they have learned to work with each other and that they help each other in different modules. Reciprocity was maintained also since the co-researchers came to sessions prepared, which not only facilitated smooth discussions and engagement in subject matters, but also made it easier for the co-researchers to share information and knowledge (Hubackova \& Semradova, 2016; Im \& Kim, 2015; Mitchell et al., 2014; Reed et al., 2015).

\section{Training and Facilitation}

Mentors as role models. The main focus of tutoring and mentoring is on reinforcing and extending subject knowledge, however, when necessary, additional focus may include remedial work, revision guidance and examination technique (Waller et al., 2017). Peck et al. (2010) view the roles of tutors as directing students' progress, supporting students and ensuring that when necessary specialist support is made available. The co-researchers expressed their appreciation for being able to access tutoring and mentoring sessions as follows:

Sizwe: Thank you for being available for us, and not being tired of us. Sometimes you had to leave, but you did not leave, you sat with us to guide us, that was helpful... you helped us through.

Lydia: ... when you asked us questions on our assignments, it helped... in that at times we don't believe in our work, so you reading every paragraph and asking us to explain really helped.

From the above, it is clear that the co-researchers benefited from having access to tutoring and mentoring sessions. During these sessions, the researcher and the co-researchers provided support where necessary in that when other co-researchers did not understand course material, those who understood the material intervened and assisted the others. This supports the functionalist notion that individuals cannot function in isolation if they want to survive and thrive in society and maintain stability. Functionalism further maintains that the functions of education include the following: to instill values, to emphasize the value of achievement and to provide equal opportunities (Ferrante, 2016; Radulović \& Krstić, 2017; Stewart \& Zaaiman, 2015). Working as a group awarded the co-researchers space where they viewed each other as equals and provided support to each other when necessary.

Confidence of mentors. Waller et al. (2017) contend that mentoring should be provided by confident and capable undergraduate students, with first-hand experience about what academic life at a university is actually like. Mentors and tutors should be role models with whom the students can relate. However, although the researcher in this study was not an undergraduate student but a former UAP student, she still fulfilled the role of a mentor.

Waller et al. (2017) discovered that students achieved better grades in formative assessments after taking part in the mentoring and tutoring programmes, and seemingly, students experienced increased confidence with theories. Additionally, lecturers also reported an "increased engagement with the subject" leading to more "enjoyment of the lessons and better subject knowledge" (p. 6). The co-researchers seemed to agree that their academic performance has improved since their participation in mentoring and tutoring programme, Thabang: “...our feedback, we are good, even our lecturer is highly impressed, we got exactly 
what we were aiming for..." Edward: "We are slaying with our marks, our facilitator even said we were annoying but in a good way". Zizi: "...we are over the moon, we are so happy with our marks, we did good... we are very happy".

The above experiences of the co-researchers agree with the findings of Waller et al. (2017, p. 8-10), and Harwood et al. (2015, p. 221), namely that students experience "increased enthusiasm" for a subject when afforded the necessary support. Additionally, lecturers were confident that students benefited from the support offered in one-on-one or small group settings. Therefore, when students are afforded support and equal distribution of resources they are in a better position to create own knowledge (Clarke, 2010). Similarly, Nkoane (cited in Piper \& Piper, 2009) suggests that when such spaces such as students to co-exist are available for students, students are in a position to make connections between their lived experiences and conditions, thereby make own reality and possibly create new reality. Therefore, success is eminent when trained and knowledgeable staff act as mentors, with the responsibility to transfer their expertise to first-year students (Harwood et al., 2015).

\begin{abstract}
Lydia: "...when you asked us questions on our assignments, it helped in that you made us aware that we need to write exactly what's in "your" (referring to co-researchers) mind, not to try to impress the person who is going to read our work. And that also helped us think of lots of different ideas..."
\end{abstract}

Rawlinson and Willimott (2016) highlight that mentorship should employ a student learning centred approach. This entails that mentoring could be delivered through informal conversations in which students probe for information and insight into the 'real undergraduate student experience' (Waller et al., 2017, p. 6). Therefore, when mentors (students) share information such as the challenges they experienced, first-year students might realise that others have had similar challenges, and were able to overcome them.

\title{
Student Agency
}

Students as change agents. According to Speirs et al. (2017), students should be partners in the co-creation of the curricula and the co-evaluation of subject related matters. It that way, there is potential that students would experience increased motivation and engagement. O'Shea et al. (2016) suggest that students should be afforded space to act as change agents and should not just be informed. Preferably, students should form partnerships with academic staff where students engage in what needs to be done in subject matters (Wanner \& Palmer, 2015).

Students with a sense of agency seem to be involved or engaged in subject matters, and collectively and collaboratively they might be able to identify challenges and strategies to overcome such challenges. Moreover, students might collaborate in sharing information and engaging in discussions, which would improve text-in-context understanding of subject related matters. However, when students are not involved and engaged they might find themselves in a position of creating new realities (Nkoane cited in Piper \& Piper, 2009), as is evident in the co-researchers' response, Sizwe and Edward said "Most of the time, when I don't understand, I apply the Cram Pass Forget (CPF) strategy and it helps".

To avoid new realities that potentially might not benefit students, students need to be engaged and not merely informed about subject related matters. As suggested below, the coresearchers seemed to benefit when engaged in subject related matters, Mamello said "We need someone to challenge us to engage in more thinking..."

Constructors of curricula. At HEIs there are curriculum expectations and developments, therefore Wanner and Palmer (2015) suggest that institutions should encourage 
student engagement as this facilitates development of independent learners. Egan (2015) suggests that students develop their own goals and curricula, and these goals should be aligned with the expectations of the curricula, which will enhance independent learning. Seemingly, when students are involved in designing the curriculum, they have the opportunity to engage more with the material by spending time on challenging subject matters.

This potentially will translate into students approaching the subject from different perspectives and engaging with others, which could facilitate higher order thinking. Darling (2015) concurs that when students are engaged in curriculum development and design, they adapt smoothly to the higher education community. The co-researchers Lydia commented as follows: "...I do formulate own questions, it helps..."

From the above, it is clear that the co-researchers developed their own questions and worked on how to answer these questions, thereby they were co-grading and co-creating subject related matters. In a way, the co-researchers developed a question paper and a memorandum, and in the researcher's view, this facilitated the learning process. Therefore, when students are afforded space to collaborate and work as a collective, they learn better, and it increases their motivation and engagement during and after classes (Hakizimana \& Jürgens, 2013).

\section{Interconnecting Programme}

Source of information. SI programmes, referred to in this study as SSS, were offered close to times of assessments such as tests and exams, and even when students had to submit assignments (Hakizimana \& Jürgens, 2013). It was conducted as such so that students can have access to information relevant to such assessments. Therefore, during this information sharing sessions, facilitators and students collectively shared suggestions on how to approach the questions and answers of assessments. These sessions seemed to be of value to students, as the co-researchers Thabang commented: “...sometimes when I don't understand, someone explain in my language, in that way I understand".

The co-researchers attested that there is value in the availability of and access to SSS. They further asserted that due to fear of embarrassment, they often were reluctant to ask questions during formal sessions (Rossouw, 2020), however SSS has provided a comfortable space to ask questions and seek clarity. One co-researcher suggested that other students in the SSS space were always willing to assist those who needed help, and that valuable information was shared among those present in that specific SSS. The co-researchers gave the impression that working in collaboration and as a collective have value, such as students sometimes provided explanations in their mother tongue, which enhanced the understanding of the subject matter.

Hakizimana and Jürgens (2013) add that during the SSS programmes, students appear comfortable, therefore, such space leads to increased cooperation, motivation, self-confidence and self-esteem. These increases were ascribed to individualised attention to students, which provided students a space where they were encouraged to probe for more information without fear of embarrassment (Rossouw, 2020).

Collaborative learning. Hakizimana and Jürgens (2013) believed that there was value in student collaborative learning. For example, in PTLEP, as in SSS, students are organised into small study groups of 5-7, which proved to be highly successful. Academic programmes such as SSS were held close to the tests and examination, as it was the time when students are more focused on their learning, and have started to prepare for tests or examinations. Each group was facilitated by students who successfully completed the module, and this seems to have contributed to improved student academic performance and retention. However, in this study 
the researcher facilitated collaborative learning among students (co-researchers). Edward said "...I am comfortable....The group has always been willing to help...."

The co-researchers attributed their improved academic performance to access to SSS. In other words, working together with others motivated and facilitated active learning. Students were able to identify difficult course content, which was then discussed during SSS sessions, and that gave them the opportunity to pay attention to sections they did not understand prior to the session. In collaboration with the researcher and the co-researchers (co-researchers \& researcher) who understood course content that others found challenging, these sections were explored by discussing the questions (Hakizimana \& Jürgens, 2013).

\section{Shortcomings of Best Practices to Improve Academic Support}

In research processes and implementation of strategy, there were shortcomings. These shortcomings allow for the revisit of the strategy implemented. During this research process, several shortcomings were identified that are discussed in this section.

Dependence. The co-researchers regarded the researcher as an expert in subject matter, e.g., sociology. The researcher was concerned that the students became dependent on her as she played the role of mentor and tutor, which could hinder their confidence and motivation (Jones \& Lau, 2010; Morley, 2012). Another scenario is where some co-researchers depended on their peers for academic assistance. However, this puts a huge amount of pressure on those students, and they struggled to engage in their studies as they felt the need to assist others (Hall \& Collins, n.d).

Lack of self-confidence seemed to play a role in students becoming dependent on whoever was willing to assist them (Briggs et al., 2012; McFarlane, 2016). The lack of confidence in this particular group of students may result from past experiences where they (coresearchers) were told that they were "rejects." Therefore, co-researchers at times seemed not to believe in themselves and their work, as Lydia suggested, saying, “....at times we don't believe in our work, so you reading every paragraph and asking us to explain really helped.

Co-researchers seemed reluctant to submit their written assignments to their facilitators if the researcher did not first read through the assignment. This shows the level of dependency on the researcher. Even though participants had minor mistakes at times with no need to be resubmitted, such behavior was observable and evident. Therefore, boundaries set were crossed as the co-researchers wanted to meet during the holidays as well.

Boundaries. One shortcoming in improving academic support to UAP students was a lack of adhering to boundaries in the relationship between the researcher and the co-researchers. McFarlane (2016) conducted a study with tutors and also found a lack of boundaries. McFarlane revealed that the tutors seemed to lack clarity on what it means to be a tutor. Other tutors did not clearly communicate boundaries to the students. Because tutors work closely with students, some students revealed personal matters that potentially hindered their engagement and success. Some tutors did not know how to handle this situation and became distressed to the extent that they could not function effectively (Hall \& Collins, n.d.; Jones \& Lau, 2010). In addition, due to time constraints, some tutors hesitated before seeking guidance from senior tutors and their mentors in cases of students' acute personal circumstances. However, there were cases where clear boundaries were set, but as a result of students relying too heavily on tutors, these boundaries were ignored. A similar situation occurred during this research study.

McFarlane (2016) suggested that setting boundaries was paramount to the success of tutoring. In the current research study, the researcher was willing to provide academic support to the co-researchers. However, she did not deem it necessary to set such strict boundaries as she believed that those students were adults and knew and understood the concept of boundaries. From Sizwe's statement, it is clear that they crossed boundaries. Sizwe said, “...even during holidays, you were available for us even when you had to spend time with your 
family. And at times, we just came and disturb your other work." The phrase "at times, we just came and disturbed your other work" is a clear example that the researcher was mistaken in assuming that the co-researchers understood and would keep to the boundaries she set. It often happened that the co-researchers did not make prior arrangements for consultations with the researcher, as indicated in Mamello's statement: “...Sometimes you had to leave, but you did not leave..." The researcher also had other commitments, such as lecturing, and sometimes the co-researchers did not find her in the office. The co-researchers would then contact her by phone or WhatsApp to ask for assistance. Because they often were behind schedule, the co-researchers left things to the last minute and then pressured the researcher for assistance. They did not see the need to delay gratification.

Time-consuming and costly. Other shortcomings that hinder the implementation of the strategy to improve academic support are time and money. There seems to be a need among UAP students for supportive systems, such as peer support, tutoring, and academic advising. Similarly, Briggs et al. (2012) believed that peer support, tutoring, and academic advising support systems enable socialization and eased adaptation to HEIs. Briggs et al. (2012) articulated that the unavailability and inaccessibility of such services might hinder student progression and retention. However, in this research study, such support services were available, enhancing the co-researchers' performance. Because support systems can take the form of staff as course co-ordinators working with small groups of first-year students (Briggs et al., 2012), institutions might need to employ more staff, making this a costly exercise. As stated earlier, the danger identified with this system is that it may lead to student dependency on peers, hindering learning and independent learning (Briggs et al., 2012; Wanner \& Palmer, 2015).

In this study, tutoring and mentoring sessions posed time constraints. The sessions were aligned with the sociology lecture time-table. Hence, the content had to be covered before the co-researchers had to complete each assessment. Additionally, the co-researchers seemed dependent on the researcher, as they often did not attend lectures because facilitators told them that they were "rejects" (Wanner \& Palmer, 2015). They furthermore had the expectations that the work would be covered during our group discussion, in other words, with peer support. The co-researchers also revealed personal matters that emotionally overwhelmed and distressed the researcher at times (Briggs et al., 2012; McFarlane, 2016). The remarks below agree with Briggs et al. (2012) and Wanner and Palmer (2015).

A limited academic support system creates student dependency on peers and, eventually, hinders learning and independent learning. This aligns with the views of Briggs et al. (2012), McFarlane (2016), and Wanner and Palmer (2015). Circumstances such as depending on the researcher and sharing personal matters often resulted in the researcher and co-researchers working until late. Some co-researchers were not productive because they were exhausted. In addition, limited face-to-face contact with facilitators added more strain on coresearchers, which is evident in Thabang's remark, "...we are scared to ask questions, which makes us not understand the work." Another issue was that co-researchers could not obtain academic support beyond formal sessions. Mamello stated the following in this regard: "...even our facilitators are not available to assist us, we noticed that they only come to campus for classes, and when did they leave. Even after class, when we try to ask questions, we don't get answers." To assist the co-researchers in achieving the desired goals, namely to pass this particular module, the researcher and co-researchers spent long hours dealing with what they considered the difficult subject matter.

Reluctance. Some students seem reluctant to use the available academic support on campus, such as learning assistance support centers. One explanation that Peck et al. (2010) and Aguilar et al. (2014) provided is that students seemed not to understand the purpose of learning assistance support centers. Furthermore, students may also choose not to access such 
services for fear of stigmatization (Aguilar et al., 2014; Peck et al., 2010). Stigmatization of those who access academic support is evident in Zizi's remark: "You know ma'am when we ask for help when we don't understand parts of a module, some people say we are dumb, even our friends say the module is easy."

From the co-researcher's perspective above, it seems as if some students were reluctant to look and ask for assistance even if they found a particular module challenging. Peck et al. (2010) and Aguilar et al. (2014) had similar findings. In addition, in Karp et al. (2008), institutions that offer UAP and related support turn to do so at a specified center.

Karp et al. (2008) attested to the need for availability and accessibility of support centers for all students, despite their education level. These centers offer various support services, such as academic advising, tutoring, and peer group sessions. However, several challenges have been reported concerning academic advising. One challenge is the limited number of faculty-specific advisors available. This leads to students receiving general academic advice that is not specific to their program of study. This arrangement tends to misdirect students and does not enhance a personalized relationship between the advisor and the student (Darling, 2015; Egan, 2015; KirkKuwaye \& Sano-Franchini, 2015; Lowenstein, 2015).

\section{Conclusion}

This paper proposes strategies and/or best practices UAPs can adapt, with the intention to improve students' academic support and in addressing inequities that seem to exist particularly at multi-campus institutions. It seems as if widening participation is prevalent and well-documented, and has proven successful in Australia. Therefore, in South African context, it is the responsibility of SAHEIs to address social inclusivity for all. That is, all HEIs need to provide equal opportunities to all its students, despite students' level of study. As in some parts of the world, initiatives and/or programmes such as; Supplemental Support Service (referred to as SI); South African Mentoring Experience (SAME) referred to as AIME; Student-Led; Individually-Created Course (SLICC); and Peer network programmes, seem to have successfully addressed, and successfully enabled students' transition and articulation to mainstream programmes and beyond. However, even though these programs in some parts of the world seemed to have worked for a particular student cohort, and have been implemented and made available for all students despite level of study. In SAHEIs that offer UAP and are multi-campused, there seems to be inequities in resources distribution. Even though the aim of this study was not to compare different campuses or student cohort, it is necessary to indicate that best practices discussed in this paper seem available at mainstream campus students (students with APS of 30 and higher), and limited for UAP students (students with APS 18-24) as these students have gained access to same institution but programmes offered at different campuses, hence the use of concept "multi-campuses" in this paper. This practice seems to perpetuate further marginalization, thereby denying UAP students a sense of collegiality.

\section{References}

Aguilar, S., Lonn, S., \& Teasley, S. D. (2014, March). Perceptions and use of an early warning system during a higher education transition program. In Proceedings of the Fourth International Conference on Learning Analytics and Knowledge (pp. 113-117). ACM.

Arendale, D. R. (2010). Access at the crossroads: Learning assistance in higher education. Jossey-Bass.

Ary, D., Jacobs, L. C., Sorensen, C., \& Razavieh, A. (2010). Introduction to research in education (8th ed.). Cengage Learning.

Babbie, E., \& Mouton, J. (2005). The practice of social research. Oxford University Press. 
Benokraitis, N. V. (2016). SOC: Introduction to sociology (Student Edition, 4th ed). Cengage Learning.

Briggs, A. R. J., Clark, J., \& Hall, I. (2012). Building bridges: Understanding student transition to university. Quality in Higher Education, 18(1), 3-21. https://doi.org/10.1080/ 13538322.2011 .614468

Chojnacki, W. (2015). Reproduction of educational inequities. Editorial Staff, 184.

Clarke, S. (2010). Building a knowledge society one individual at a time: A multi-level review [Working Paper]. MSMB.

Creswell, J. W. (2012). Educational research: Planning, conducting and evaluating quantitative and qualitative research (4th ed.). Pearson.

Darling, R. (2015). The academic adviser. The Journal of General Education, 64(2), 90-98. http://www.jstor.org/stable/10.5325/jgeneeduc.64.2.0090

Diaz, M., Cheng, S., Goodlad, K., Sears, J., Kreniske, P., \& Satyanarayana, A. (2021). Turning Collective Digital Stories of the First-year Transition to College into a Web of Belonging. American Journal of Qualitative Research, 5(1), 67-84. https://doi.org/10.29333/ajqr/10793

Egan, K. (2015). Academic advising in individualized major programs promoting the Three I's of general education. The Journal of General Education, 64(2), 75-89. http://www.jstor.org/stable/10.5325/jgeneeduc.64.2.0075

Ferrante, J. (2013). Sociology: A global perspective. Cengage Learning.

Ferrante, J. (2016). Sociology: A global perspective. Cengage Learning.

Gale, T., \& Parker, S. (2014). Navigating change: A typology of student transition in higher education. Studies in Higher Education, 39(5), 734-753. https://doi.org/10.1080/ 03075079.2012.721351

Hakizimana, S., \& Jürgens, A. (2013). The peer teaching/learning experience program: An analysis of students' feedback. Alternation (Special Edition), 9, 99-127.

Hall, M., \& Collins, S. (n.d.). Towards a widening participation perspective on peer assisted learning. University of Winchester.

Harwood, V., McMahon, S., O’Shea, S., Bodkin-Andrews, G., \& Priestly, A. (2015). Recognising aspiration: The AIME program's effectiveness in inspiring indigenous young people's participation in schooling and opportunities for further education and employment. The Australian Association for Research in Education, 42(2), 217-236.

Hilsdon, J. (2014). Peer learning for change in higher education. Innovations in Higher Education \& Teaching International, 51(3), 244-254. https://doi.org/10.1080/14703297.2013.796709

Hlalele, D. L. (2010). Do learning skills acquired in the university access program enhance participation in academic practice? SAJHE, 24(1), 98-110.

Hubackova, S., \& Semradova, I. (2016). Evaluation of blended learning. Procedia - Social and Behavioral Sciences, 217, 551-557. http://creativecommons.org/licenses/by-nc-nd/4.0/

Im, J., \& Kim, J. (2015). Use of blended learning for effective implementation of Englishmedium instruction in a non-English higher education. International Education Studies, 8(11), 1-15. http://dx.doi.org/10.5539/ies.v8n11p1

Jones, N., \& Lau, A. M. S. (2008). Blending learning: Widening participation in higher education. Innovations in Education and Teaching International, 47(4), 405-416. https://doi.org/10.1080/14703297.2010.518424

Kaldi, S., \& Griffiths, V. (2013). Mature student experiences in teacher education: Widening participation in Greece and England. Journal of Further \& Higher Education, 37(4), 552-573. https://doi.org/10.1080/0309877X.2011.645468

Karp, M. M., O'Gara, L., \& Hughes, K. 1. (2008). Do support services at community colleges encourage success or reproduce disadvantage? An exploratory study of students in two 
community colleges [Working Paper No. 10]. Community College Research Center, Columbia University. https://files.eric.ed.gov/fulltext/ED499920.pdf

Kirk-Kuwaye, M., \& Sano-Franchini, D. (2015). "Why do I have to take this course?" How academic advisers can help students find personal meaning and purpose in general education. The Journal of General Education, 64(2), 99-105. https://www.jstor.org/ stable/10.5325/jgeneeduc.64.2.0099

Lazar, M. M. (Ed.) (2005). Feminist critical discourse analysis: Gender, power and ideology in discourse (2nd ed.). Palgrave Macmillan.

Lowenstein, M. (2015). General education, advising, and integrative learning. The Journal of General Education, 64(2), 117-130. http://www.jstor.org/stable/10.5325/jgeneeduc.64.2.0117http://www.jstor.org/stable/1 0.5325/jgeneeduc.64.2.0117.

Mahlomaholo, S. (2009). Critical emancipatory research and academic identity. Africa Education Review, 6(2), 224-237. https://doi.org/10.1080/18146620903274555https://doi.org/10.1080/18146620903274 555

Marais, F. C., \& Hanekom, G. (2014). Innovation in access: 25 years of experience in access programs. In Annual Teaching and Learning Report 2014: Moving the needle towards success (pp. 10-12). University of the Free State: Centre for Teaching and Learning.

Marincowitz, G. J. (2003). How to use participatory action research in primary care. Family Practice, 20(5),

595-600. https://doi.org/10.1093/fampra/cmg518https://doi.org/10.1093/fampra/cmg518

McFarlane, K. J. (2016). Tutoring the tutors: Supporting effective personal tutoring. Active Learning in Higher Education, 17(1), 77-88. https://doi.org/10.1177/ 1469787415616720

Merton, R. K. (1937). The sociology of knowledge. Isis, 27(3), 493-503. http://www.jstor.org/stable/225155http://www.jstor.org/stable/225155

Mitchell, L. D., Parlamis, J. D., \& Claiborne, S. A. (2015). Overcoming faculty avoidance of online education: From resistance to support to active participation. Journal of Management Education, 39(3), 350-371. https://doi.org/10.1177/1052562914547964

Morley, L. (2012). Widening participation in higher education in Ghana and Tanzania. International Higher Education, 67, 21-23. www.sussex.ac.uk/education/cheer/wphegt.

Neuman, W. L. (2014). Social research methods: Qualitative and quantitative approaches. Pearson.

Nkonyane, V. (2014). Power knowledge contestations at a transforming Free State higher education institution: Learning guide as a metaphor. Higher Education of Social Science, $7(1), \quad 14-21$. http://www.cscanada.net/index.php/hess/article/view/5279http://www.cscanada.net/in dex.php/hess/article/view/5279

O'Shea, S., Lysaght, P., Roberts, J., \& Harwood, V. (2016). Shifting the blame in higher education - Social inclusion and deficit discourses. Higher Education Research \& Development, 35(2), 322-336. https://doi.org/10.1080/07294360.2015.1087388https://doi.org/10.1080/07294360.201 5.1087388

Pascoe, G. (2014). Research matters. In F. du Plooy-Calliers \& C. Davis (Eds.), Research matters. Paarl Media. Juta.

Peck, J., Chilvers, L., \& Lincoln, Y. (2010). Learning support: Student perceptions and preferences. Art, Design \& Communication in Higher Education, 9(2), 135-149. https://doi.org/10.1386/adch.9.2.135_1

Piper, H., \& Piper, J. (2009). Educational research and transformation in South Africa. Science Africa. 
Radulovic, L. M., \& Krstic, S. M. (2017). Social inequality in education analyzed within various theoretical frameworks. Philosophy, Sociology, Psychology \& History, 16(1), 25-36. https://doi.org/10.22190/FUPSPH1701025M

Rawlinson, C., \& Willimott, M. (2016). Social justice, learning centredness and a first year experience peer mentoring program: How might they connect? Journal of Peer Learning, 9, 41-48. https://ro.uow.edu.au/ajpl/vol9/iss1/5

Reed, R., King, A., \& Whiteford, G. (2015). Re-conceptualising sustainable widening participation: Evaluation, collaboration and evolution. Higher Education Research \& Development, 34(2), 383-396. https://doi.org/10.1080/07294360.2014.956692

Rossouw, L. (2020). Skills and competencies for lifelong learning. Department of Psychology. University of the Free State, Bloemfontein.

Segabutla, M. H., \& Evans, R. (2019). Lack of lecturer clarity during instruction: Possible reason for poor throughput? South African Journal of Higher Education, 33(3), 115131. http://dx.doi.org/10.20853/33-3-2224

Sekonyela, L. (2021). Student challenges with the University Access Program in South Africa. Journal of Ethnic \& Cultural Studies, 8(1), 239-269. http://dx.doi.org/10.29333/ejecs/592

Speirs, N. M., Riley, S. C., \& Mccabe, G. (2017). Student-led, individually-created courses: Using structured reflection within experiential learning to enable widening participation students? Transition through and beyond higher education. Journal of Perspectives in Applied Academic Practice, 5(2), 50-57. https://doi.org/10.14297/jpaap.v5i2.274

Stewart, P., \& Zaaiman, J. (2015). Sociology: A South African introduction. Juta.

Strydom, H., Fouche, C. B., \& Delport, C. S. L. (2004). Research at grass roots: For the social sciences and human service professions.

Waller, R., Mathers, A., Savidge, P., Flook, G., \& Hamm, D. (2017). Engaging sociologists: An A-Level tutoring and mentoring outreach project with 2nd year undergraduate students. The Sociology Teacher, 6(2), 4-11. https://www.britsoc.co.uk/media/ 24364/spring_2017_tst_vol_6_2.pdf

Wanner, T., \& Palmer, E. (2015). Personalising learning: Exploring student and teacher perceptions about flexible learning and assessment in a flipped university course. $\begin{array}{llll}\text { Computers } \& \quad \text { Education, } & 88,\end{array}$ http://dx.doi.org/10.1016/j.compedu.2015.07.008http://dx.doi.org/10.1016/j.compedu. 2015.07.008

Weninger, C. (2012). Codes as process. In L. S. Given (Ed.), The SAGE encyclopedia of qualitative research methods. SAGE Publications. https://edge.sagepub.com/system/files/Ch10CodesandCoding.pdfhttps://edge.sagepub. com/system/files/Ch10CodesandCoding.pdf

Wildemuth, B. M. (2009). Applications of social research methods to questions in information and library science. Libraries Unlimited.

Wilson-Strydom, M. (2015). University access and theories of social justice: Contributions of the capabilities approach. Higher Education, 69, 143-155. https://doi.org/10.1007/ s10734-014-9766-5

Wodak, R., \& Meyer, M. (2009). Methods of Critical Discourse Analysis (2 ${ }^{\text {nd }}$ ed). Sage Publication, London. 


\section{Notes on Contributors}

Lerato M Sekonyela, is a Module Coordinator in the Department of Sociology, and Academic Facilitator at the Department of Psychology in University Access Programme at the University of the Free State (UFS) in South Africa. She teaches Skills and Competencies for Lifelong Learning. Her research interest(s) have centred on University Access Programme: students experienced challenges, and a strategy to improve the academic support of first-year students in a university access programme. Dr. Sekonyela received her $\mathrm{PhD}$ in Education with specialization in Higher Education Studies from University of the Free State in 2019. 